\title{
EMPRESAS BRASILEIRAS ADOTAM POLÍTICAS DE LOGÍSTICA REVERSA RELACIONADAS COM O MOTIVO DE RETORNO E OS DIRECIONADORES ESTRATÉGICOS?
}

\author{
Adilson Aderito da Silva \\ Doutor em Administração de Empresas pela Universidade Presbiteriana Mackenzie \\ Professor da Universidade Presbiteriana Mackenzie \\ asilva@mackenzie.br \\ Paulo Roberto Leite \\ Mestre em Administração de Empresas pela Universidade Presbiteriana Mackenzie \\ Professor da Universidade Presbiteriana Mackenzie \\ leitepr@mackenzie.com.br
}

\begin{abstract}
RESUMO
O crescimento do consumo e a satisfação das exigências dos segmentos de mercado têm produzido significativas alterações no processo logístico de retorno dos produtos não consumidos. Retornos esses motivados por erros de expedição, excessos nos canais de vendas, padrão de qualidade dos produtos e defeitos passíveis de reparos. Essas alterações, têm tornado mais visível a atividade da Logística Reversa, que se ocupa com o planejamento das operações com produtos de retorno mediante adoção de direcionadores estratégicos, com o objetivo de recuperar valor econômico, melhorias na imagem e os serviços prestados. A partir da revisão de estudos sobre Logística Reversa foi levantada a seguinte questão de pesquisa: como os direcionadores estratégicos de Logística Reversa estão relacionados com os motivos do retorno e as políticas empresariais para destinação dos produtos de retorno? Para responder tal questão, foi conduzida uma pesquisa com 188 executivos que responderam um questionário, com assertivas sobre os motivos de retorno, direcionadores estratégicos da Logística Reversa e políticas adotadas. Esses dados, examinados à luz da técnica de modelagem por equações estruturais, revelaram uma influência significativa dos motivos de retorno sobre os direcionadores de Logística Reversa que determinam as políticas de retorno adotadas pelas empresas pesquisadas.
\end{abstract}

Palavras-chave: Cadeia de suprimentos; Logística reversa; Produtos de retorno; Valor econômico.

\section{DO BRAZILIAN COMPANIES ADOPT POLICIES OF REVERSE LOGISTICS RELATED TO THE REASON OF RETURN AND STRATEGIC DRIVERS?}

\begin{abstract}
The growth of consumption and the search to satisfy all market segments have inspired important changes in companies, specifically regarding the process of returning products. Returns are motivated by several reasons including: shipping errors, excesses in the sales channels, and product quality. Due to these changes, the reverse logistics activities, which deal with planning and operation of product returns with economic, service or image drivers, becomes more visible nowadays. From literature reviews about Reverse Logistics, the research question was selected: are the reasons for return and strategic drivers of reverse logistics programs related to the companies' policies? A survey research project was conducted with 188 executives. Each executive completed a questionnaire with statements about the return reason, strategic drivers of reverse logistics, and policy adopted by companies. The data were examined by a structural equation technique and revealed that return reasons have influence on the reverse logistics drivers, which results in return policies adopted by the companies surveyed.
\end{abstract}

Keywords: Reverse logistics; Supply chain; Economic values; Returned products. 


\section{INTRODUÇÃO}

Até há pouco tempo, as empresas ignoravam as quantidades de produtos não consumidos ou, com pouco uso, que retornavam do mercado em razão da pequena representatividade dessas quantidades quando comparadas com o volume de mercadorias distribuídas para mercado. Assim, o retorno desses produtos, denominados produtos do retorno de pós-venda, não representava maiores dificuldades para o posicionamento empresarial quanto ao equacionamento dos processos de logística reversa, caracterizados, até então, pela parca disponibilidade de recursos e pela frágil visibilidade da logística reversa nas empresas.

Com a transformação da economia para uma dimensão global, uma maior variedade de produtos passou a ser lançada, a cada instante no mercado, em significativas quantidades. Essa variedade de novos produtos, aliadas aos novos hábitos de consumo, às novas formas de competitividade, às novas legislações ambientais e de defesa do consumidor e, uma maior preocupação dos gestores com a exposição da imagem corporativa, são as principais causas apontadas para o aumento do retorno de produtos.

Os motivos típicos do retorno, por sua vez, podem ser entendidos como devidos a produtos defeituosos, rejeição por arrependimento do consumidor, falta de entendimento de manual, validade do produto, término de moda ou de estação de produtos, baixo giro dos estoques, lançamento de novos modelos, entre outros, de uma lista relativamente grande de possibilidades.

Tais fatos têm levado as empresas a experimentar grandes mudanças no que tange ao gerenciamento e a destinação das mercadorias ainda não consumidas, ou de pós-venda (Leite, 2003). Com isso, o retorno desses produtos passou a ser um motivo de preocupação das empresas e do governo, em todos os setores industriais e com as mais variadas modalidades de produtos nos diversos elos das cadeias reversas.

A literatura consultada sobre Logística Reversa expõe a existência de diferenças entre políticas adotadas pelas empresas, ao tratar do retorno de produtos por conta do ramo empresarial, do valor agregado do produto retornado, da posição na cadeia de suprimentos, do motivo de retorno e dos objetivos estratégicos (drivers) envolvidos.

Observa-se igualmente que a investigação acadêmica está concentrada, especialmente, em estudos de casos empresariais, revelando carência apreciável de estudos em ambiente de cadeia de suprimento focados no relacionamento entre os motivos de retorno, os objetivos estratégicos da empresa, os procedimentos empregados, os recursos disponibilizados, os indicadores dos processos de retorno e os destinos dos produtos retornados.

Para tentar suprir essa lacuna, se propõe como objetivo principal deste artigo, analisar o relacionamento entre os motivos de retorno, os direcionadores estratégicos da Logística Reversa e o destino dos produtos de retorno. Portanto, busca-se, com este estudo, responder a seguinte questão de pesquisa: como os direcionadores estratégicos de Logística Reversa estão relacionados com os motivos do retorno e as políticas empresariais para destinação dos produtos de retorno?

Para tal, foram estabelecidos os seguintes objetivos específicos: (a) empreender ampla revisão dos estudos na Área de Logística Reversa para levantar os principais motivos do retorno de produtos; os direcionadores estratégicos de Logística Reversa adotados nas empresas e os destinos dos produtos que retornam do mercado; (b) elaborar um instrumento de pesquisa para coletar dados junto aos gestores na cadeia de suprimentos; (c) propor um modelo para estimar, pela ótica dos gestores, os parâmetros de análise do relacionamento entre os construtos "motivos do retorno"; "direcionadores estratégicos de Logística Reversa" e o "destino dos produtos de retorno".

Inicialmente, apresenta-se o referencial teórico, constituído pela revisão bibliográfica realizada onde se abordará os principais aspectos de interesse e fundamentação dos construtos propostos no artigo, seguindo-se a metodologia onde são apresentados os modelos da pesquisa e técnicas estatísticas correspondentes; a apresentação e análise dos resultados da pesquisa e, finalmente, as considerações e sugestões dos autores para os próximos estudos. 


\section{FUNDAMENTAÇÃO TEÓRICA}

Neste tópico, serão resumidos os principais elementos da revisão bibliográfica realizada na pesquisa que permitiram o estabelecimento dos diferentes critérios examinados, bem como as dimensões de maior interesse e as bases conceituais utilizadas na investigação.

\subsection{Logística reversa - conceitos principais}

Diversos são os exemplos que tornam visíveis as quantidades crescentes de produtos atualmente produzidos, alimentando hábitos de consumo de posse por múltiplos bens da mesma espécie nos mais diversificados setores de consumo. Por outro lado, não menos importante, também contribui para esta profusão de produtos no mercado atual, a crescente variedade de modelos em cada categoria de produtos para satisfazer as necessidades especificas e o desejo de cada grupo de consumidor ou cliente na cadeia de suprimentos.

As produções em larga escala e de alta flexibilidade ganham atenção de todas as indústrias, tornando-se globais e distribuídas ao longo do planeta. É neste cenário, de quantidades crescentes e alta variedade de produtos no mercado em todo o globo, que também aumenta o retorno de produtos do mercado, sem uso ou após o seu uso, dando maior visibilidade a esta nova área denominada Logística Reversa (Cairncross, 1992; Donaire, 1999, De Brito, Dekker, 2002; Hartman, 1996; Leite, 2003; Poulen e Farris, 1992; Sheth e Parvatiyar, 1995).

Compêndios de logística empresarial ou de outras áreas do conhecimento, até poucas décadas, nada ou pouco mencionavam em relação ao fluxo de retorno de produtos provenientes do mercado, no sentido oposto ao de sua distribuição, com origem no consumidor final ou em outro integrante da cadeia de suprimentos. Este fluxo e os elos que constituem o retorno dos produtos, não consumidos ou já consumidos, são reconhecidos mais recentemente nos livros especializados de logística empresarial e em livros de outras áreas de conhecimento como canais de distribuição reversos (Ballou, 2001; Bowersox, Closs, 2001; Faria e Costa, 2005; Pires, 2004; Handfield e Nichols, 1999; Harrison e Hoek, 2005; Novaes, 2007; Stock, 1998).

Sinteticamente, utilizando a nomenclatura de Leite (2003), a Logística Reversa pode ser entendida como uma área que visa planejar, controlar e operacionalizar estes fluxos reversos de produtos não consumidos (pós-venda) ou de produtos já consumidos (pós-consumo). Inicialmente definida como uma área da logística empresarial, envolve aspectos puramente operacionais do retorno dos produtos e tem sido entendida mais recentemente de forma mais ampla e estratégica, como uma área de preocupações relacionadas ao equacionamento dos fluxos de retorno de produtos.

$\mathrm{O}$ aspecto estratégico mais recentemente passou a ser relacionado à crescente preocupação com a sustentabilidade e com imagem empresarial, o que garante à Logística reversa uma posição na reflexão estratégica empresarial em empresas contemporâneas (Carter e Ellram, 1998; Daugherty, 2004; De Brito, 2004; Dowlatshahi, 2005; Kopicki et al, 1993;; Langman, 2001; Rogers e TibbenLembke, 2001;).

Considerando a importância que os fluxos reversos assumem, o Supply Chain Management Professional (SCMP), anterior Council of Logistics Management (CLM), conselho que orienta as principais definições sobre esta área nos Estados Unidos, alterou a definição de Logística Empresarial em 2002, englobando estes fluxos nos seguintes termos:

Logística empresarial é a parte do Supply Chain Management que planeja, implementa e controla o eficiente e efetivo fluxo direto e reverso, a estocagem de bens, serviços e as informações relacionadas entre o ponto de origem e o ponto de consumo, no sentido de satisfazer as necessidades do cliente (SCMP, 2002)

Corroborando com esta visão moderna da cadeia de suprimentos, Bowersox e Closs (2001) desenvolveram a ideia de apoio ao ciclo de vida do produto, entendendo a logística atual como um ciclo que se fecha como os fluxos reversos. Leite (2009), por sua vez, lembra a ideia Extended 
Product Responsability(EPR) (Responsabilidade Estendida do Produto), segundo a qual a responsabilidade dos fabricantes dos produtos não se encerra ao entregá-los no mercado, mas é estendida à responsabilidade pelo seu retorno.

Srivastava (2007) coloca ainda que a Logística Reversa pode ser considerada uma parte de uma disciplina mais ampla, definida pelo autor como o "Green Supply Chain Management" que englobaria desde as ideias de projeto do produto, a seleção dos suprimentos, os processos de manufatura, a distribuição dos produtos e o gerenciamento do fim de vida dos produtos.

A partir destas ideias, percebe-se que a Logística Reversa deve ser considerada como uma nova área de estudos que envolve diversas outras áreas de conhecimento e que ultrapassa a simples visão pura e operacional, para influir na estratégia empresarial com o objetivo do atender as necessidades de diversos públicos interessados, por exemplo, os seus acionistas, a sociedade, o governo e os seus funcionários.

Para melhor entender as categorias e dimensões de estudo da Logística Reversa, Leite (2005) apresenta uma relação de elementos encontrados na literatura e que foram em parte utilizadas nesta pesquisa. A figura 1 a seguir, resume as ideias do autor, enumerando estas dimensões sob diferentes perspectivas.

\begin{tabular}{|c|c|}
\hline $\begin{array}{c}\text { Categorias de Estudo em Logística } \\
\text { Reversa }\end{array}$ & Dimensões identificadas nos autores \\
\hline $\begin{array}{l}\text { Tipo de cadeia reversa pelo critério do } \\
\text { processo principal. } \\
\text { 1. Retorno } \\
\text { 2. Reparos / Reciclagem } \\
\text { 3. Embalagem retornável }\end{array}$ & $\begin{array}{l}\text { CLM: Recall, reparos, redistribuição de estoques, reuso e reciclagem. } \\
\text { RLEC: Reparo, reforma, remanufatura, canibalização, reciclagem. } \\
\text { REVLOG: Reparo, reforma, remanufatura, reciclagem, incineração. } \\
\text { FULLER: Reuso - reciclagem -incineração } \\
\text { LEITE: Pós-venda = retorno; Pós-consumo= reuso, desmanche, reciclagem. }\end{array}$ \\
\hline $\begin{array}{l}\text { Origem do retorno. Local onde se } \\
\text { inicia o retorno: } \\
\text { 1. Varejo } \\
\text { 2. Consumidor } \\
\text { 3. Empresa }\end{array}$ & $\begin{array}{l}\text { CLM: Fabricantes, distribuidores, outlets de varejo, varejo. } \\
\text { RLEC: equilíbrio de estoques, fim de vida ou de estação, danificados em } \\
\text { trânsito, defeituosos, não desejados, recall, aspectos ecológicos. } \\
\text { REVLOG: excesso de matérias-primas, retorno de controle de qualidade, } \\
\text { subprodutos, recall, retorno B2B comercial, ajustes de estoque, retornos } \\
\text { funcionais, retorno B2C comercial, garantia, serviço, fim de uso, fim de vida. } \\
\text { FULLER: Fontes de materiais em fim de vida útil } \\
\text { LEITE: retorno de produtos com nenhum ou pouco uso, produtos usados em } \\
\text { condições de reuso ou em fim de vida útil, resíduos industriais. }\end{array}$ \\
\hline $\begin{array}{l}\text { Objetivos estratégicos que justificam a } \\
\text { implementação da logística } \\
\text { ("drivers"). } \\
\text { 1. Econômico } \\
\text { 2. Legal } \\
\text { 3. Serviços } \\
\text { 4. Ecológico } \\
\text { 5. Imagem corporativa }\end{array}$ & $\begin{array}{l}\text { CLM: Reaproveitamento de materiais com valor econômico, diferenciação } \\
\text { em serviços, cumprimento de leis, redução de riscos ambientais, adaptação de } \\
\text { projeto dos produtos para logística reversa. } \\
\text { RLEC: Razões de competitividade e cidadania corporativa, limpeza de canal, } \\
\text { dispositivos legais, recaptura de valor econômico, recuperação de ativos, } \\
\text { proteção de margens de lucro. } \\
\text { REVLOG: Econômicos: ganhos diretos e indiretos. Legislativos: direitos do } \\
\text { consumidor, proambiental. Cidadania corporativa } \\
\text { FULLER: Tecnologia, escala econômica, participante do canal reverso, } \\
\text { mercado para os produtos reaproveitados } \\
\text { LEITE: Econômicos, legais, ecológicos, imagem. }\end{array}$ \\
\hline $\begin{array}{l}\text { Estrutura empresarial da distribuição } \\
\text { reversa da cadeia reversa analisada. } \\
\text { 1. Integrada } \\
\text { 2. Não-Integrada }\end{array}$ & $\begin{array}{l}\text { CLM: Ciclo fechado= o utilizador se ocupa da recuperação dos produtos e os } \\
\text { utilizam para novos produtos. Ciclo aberto = o utilizador pode se ocupar da } \\
\text { recuperação dos produtos, mas não os utilizam } \\
\text { REVLOG: Empresas da cadeia direta; empresas especializadas em logística } \\
\text { reversa, instituições governamentais, negócios de oportunidade. } \\
\text { LEITE: Integradas, semi-integradas e não-integradas. Ciclos abertos e } \\
\text { fechados em cadeias de pós-consumo }\end{array}$ \\
\hline $\begin{array}{l}\text { Prestadores de serviços em logística } \\
\text { reversa. } \\
\text { 1. Transporte } \\
\text { 2. Reciclagem } \\
\text { 3. Outros }\end{array}$ & $\begin{array}{l}\text { CLM: Especializados em coleta/consolidação de produtos de alto valor } \\
\text { agregado; coletores de resíduos recicláveis; coleta e processamento de } \\
\text { materiais; coletores e locadores de pallets e embalagens retornáveis. } \\
\text { Serviços de courier, de reciclagem, de transporte. } \\
\text { RLEC: Liquidadores de encerramento de vendas, de mercadorias sazonais, }\end{array}$ \\
\hline
\end{tabular}


Destino final dos produtos retornados.

1. Disposição final

2. Revenda ao comércio

3. Reciclagem

4. Devolução ao cliente após conserto

negociadores, empresas de seguro, negociadores de trocas de produtos, entre empresas.

REVLOG: Empresas especializadas em logística reversa

RLEC: Produtos: retorno para o fornecedor, revenda, venda em outlet, salvados, reforma, remanufatura, reciclagem, aterro sanitário.

Embalagem: reuso, conserto, reciclagem, salvados

REVLOG: Processo direto: reuso / revenda / redistribuição: Processo de reaproveitamento: reparo, reforma, remanufatura, reciclagem, incineração.

LEITE: Retorno ao vendedor, venda como novo, venda em mercado secundário, doação, remanufatura, reciclagem, aterro sanitário

Figura 1 - Categoria e dimensões da Logística Reversa

Figura 1(cont.) - Categorias e dimensões de estudo da Logística Reversa

Fonte: Leite, 2005

\subsubsection{Evolução dos estudos sobre Logística Reversa}

Dekker et al. (2004), na tentativa de classificar os tipos de estudos que têm caracterizado as pesquisas em Logística Reversa, distinguem, principalmente, três áreas de estudos: (a) Estudos envolvendo o gerenciamento da coleta e distribuição de produtos em fim de vida: caracterizando esta categoria de estudos pela preocupação na descrição e entendimento da rede logística de retorno e redistribuição, dando ênfase aos produtos de pós-consumo retornados; (b) Estudos direcionados ao entendimento do planejamento e estoques na produção, os fluxos dos produtos retornados dentro da empresa e sua relação com o fluxo direto de envio de produtos novos ao mercado; (c) Estudos sobre a logística reversa no Supply Chain Management (SCM), envolvendo, desta maneira, os estratégicos e o relacionamento entre os elos das cadeias diretas e reversas; (d) Rubio et al. (2005), retomando estas definições, analisam artigos acadêmicos sobre Logística Reversa em 26 revistas europeias e americanas, desde 1995 até 2005, obtendo as seguintes conclusões nesta amostra: (1)Quantidade de artigos publicados: o número de publicações passou de quatro artigos em 1999 para 35 artigos em 2005; (2) Tipo de estudos segundo a nomenclatura de Dekker et al.( 2004): 56,45\% destes artigos referiam-se à área de planejamento de estoques ou de produção; $31,18 \%$ à área de estratégicas e ao SCM e 12,27\% a estudos sobre a rede logística reversa e o fim de vida de produtos; (3) Metodologia utilizada: $65,05 \%$ dos artigos analisados usavam técnicas matemáticas de modelagem em sua metodologia; $21,51 \%$ dos estudos usavam técnicas qualitativas de pesquisa em estudos de caso, e o restante, distribuído entre revisão bibliográfica $(3,23 \%)$, teóricos $(5,38 \%)$ e survey $(4,84 \%)$; (4)País de origem dos autores: principalmente Alemanha, Holanda e USA.

Levantamento realizado por Brito et al. (2008), no Brasil, revela também um apreciável crescimento no número de artigos apresentados em selecionados congressos brasileiros nestes últimos anos, revelando uma evolução de 1 (um) único artigo em 2000 para 20(vinte) em 2007. Abukhader e Johnson (2004) investigaram a relação do tema logística e supply chain com o tema meio ambiente, analisando artigos em 27 revistas acadêmicas publicadas entre os anos 1992 e 2001. Identificam três grandes categorias de estudos: o grupo de Logística Reversa, o de Suply Chain verde e o de impactos da logística no meio ambiente. De acordo com estes autores, as investigações predominantes referem-se a negócios entre empresas com menor interesse no que se refere as relações entre logística e o meio ambiente.

Por estes levantamentos, embora preliminares e amostrais, é possível verificar que o interesse em pesquisas nesta área tem crescido de forma apreciável. No entanto, mostram diversas lacunas ou espaços para estudos ainda não explorados, entre outros uma área de estudos envolvendo a busca de melhor entendimento do comportamento das empresas em relação à Logística Reversa, que justifica a preocupação focal desta pesquisa.

A literatura pesquisada sobre o tema Logística Reversa permite relacionar em poucas linhas, sem pretensões de exaustão, as principais ideias encontradas e seus autores contributivos para o avanço dos estudos nesta área. Kopicki et al. (1993) apresentam um resumo sobre os principais conceitos da Logística Reversa.

Revista de Gestão Social e Ambiental - RGSA, São Paulo, v. 6, n. 2, p. 79-92, maio/ago. 2012. 
Fuller et al. (1995), em uma coleção sobre o tema de Marketing Verde, abordam o ciclo fechado de reciclagem. Leite (1998) propõe categorias preliminares dos canais reversos. Rogers e Tibben-Lembke (1999) pesquisaram o mercado americano com uma visão de negócios e de hábitos empresariais. Carter e Ellram (1998) propuseram uma estrutura para o estudo da Logística Reversa.

Dornier et al. (2000) sugeriram a extensão do conceito de logística empresarial, propondo que englobem os canais reversos. Dowlatshahi (2000; 2003) sugeriu uma abordagem estratégica e operacional para a Logística Reversa e sua aplicação em estudo de caso. Já Bowersox e Closs (2001) ressaltaram a importância de garantir o ciclo de vida dos produtos após o seu final de vida útil.

Majumder e Groenevelt (2001) examinaram o modelo de reutilização de componentes em remanufatura. Fleischman $(2001 ; 2003)$ aplica modelo matemático ao processo de retorno de produtos para remanufatura. Ferguson e Browne (2001) realizaram trabalho sobre a importância das informações na Logística Reversa de pós-consumo. Já Leite (2002) sugeriu a subdivisão das áreas de estudo da Logística Reversa em pós-venda e pós-consumo. De Brito e Dekker (2002) desenvolveram uma proposta para decisões estratégicas e táticas em Logística Reversa.

Giuntini e Gaudette (2003) trataram os canais reversos de remanufatura enfatizando sua importância econômica. Leite (2003) estabeleceu o modelo relacional entre os diversos direcionadores de programa. Daugherty (2004) estudou a importância dos recursos disponibilizados e das informações na Logística Reversa. Leite (2005) relacionou as diversas dimensões e categorias da Logística Reversa. Tan e Kumar (2006) desenvolveram modelo de simulação para a decisão de remanufatura. Brito, Leite e Silva (2008) apresentaram os hábitos empresariais brasileiros em Logística Reversa.

Observa-se, por esta breve revisão, a grande diversificação de enfoque possível no estudo da Logística Reversa, o que abre oportunidades de estudos acadêmicos no futuro.

\subsection{Motivos de retorno de produtos não-consumidos}

De acordo com Leite (2009), se distinguem, pelo menos, três grandes categorias de motivos que justificam o retorno de produtos não-consumidos ou de retorno de pós-venda: retornos por motivos comerciais, por defeitos ou qualidade em geral e por validade expirada.

Entre os motivos comerciais, o autor identificou erros de expedição, falta de giro nos estoques, contratos de consignação, término de uma estação, entrada de novos modelos, entre outros motivos.

$\mathrm{Na}$ categoria de defeituosos, citou os serviços de pós-venda para conserto ou troca de componentes, produtos danificados em trânsito e os casos em que o produto admite extinção de validade. Na Figura 2, estão resumidas as ideias desse autor que serviram de base conceitual para esta pesquisa, onde se identificam os destinos dados a cada categoria de retorno considerado.

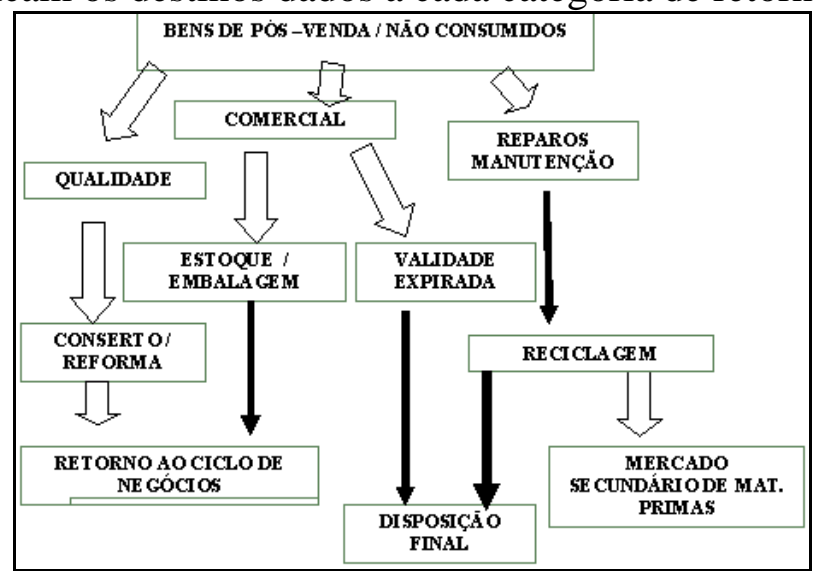

Figura 2: Fluxo e motivos de retorno de pós-venda

Fonte: Adaptado de Leite (2003) 


\subsection{Políticas e procedimentos adotados no retorno dos produtos}

Diversas são as atitudes possíveis das empresas quanto ao retorno de produtos ainda não consumidos. Com maior ou menor liberalidade, as empresas poderão adotar diferentes atitudes reveladas pelo nível de recursos colocados à disposição do retorno de seus produtos, que variarão de acordo do impacto que o retorno poderá causar em suas atividades.

Os direcionadores estratégicos orientarão, de acordo com certos limites naturais, o nível de disponibilidade de seus ativos empresariais, de mão de obra e de recursos financeiros colocados à disposição dos sistemas de coleta, transportes, informações, armazenagem, treinamento de especialistas, procedimentos de retorno e sistema de indicadores de desempenho, entre outros aspectos (Brito et al, 2005; De Brito, 2004; Kopicki et al., 1993; Leite, 2006; Rogers; TibbenLembke, 1998; Stock, 1998).

Estas políticas foram relacionadas por Brito et al. (2005) reproduzidas na figura 3, a seguir, com as quais, mediante um critério de pontuação, tornaram objetiva a mensuração destas atitudes empresariais com relação aos recursos colocados a disposição para o retorno de produtos.

\begin{tabular}{|l|l|}
\hline PROCEDIMENTOS GERAIS & $\begin{array}{l}\text { ARMAZENAGEM E RECURSOS } \\
\text { - Procedimentos de retorno definidos }\end{array}$ \\
- Controle do recebimento de retornos & - Áreas específicas destinadas à remanufatura \\
- Classificação e quantificação do retorno & - Controle dos custos de armazenagem do retorno \\
- Codificação dos retornos por controles & - Pessoal dedicado ao retorno \\
- Procedimentos de consolidação do retorno & - Equipamentos dedicados ao retorno \\
- Procedimentos de seleção e destino definidos & - Sistemas de informação dedicados ao retorno \\
\hline TRANSPORTE & REVALORIZAÇÃO \\
- Meios e veículos definidos & - Motiva o tratamento do retorno \\
- Frequência e trajeto de coleta definidos & - Proporciona ganho de imagem \\
- Acondicionamento definido do retorno & - Proporciona recuperação de valor \\
- Prioridade do retorno & - Custo e receita conhecidos \\
- Controle de custos de transportes do retorno & - Mercados secundários definidos \\
\hline $\begin{array}{l}\text { CONTRATOS } \\
\text { - Contratos de retorno junto à cadeia }\end{array}$ & $\begin{array}{l}\text { FLUXO DE INFORMAÇÕES } \\
\text { - Contratação de terceiros contratados para revalorização } \\
\text { - Fluxo de pagamentos e ressarcimentos }\end{array}$ \\
\hline
\end{tabular}

Figura 3: Componentes do nível de estruturação de um canal reverso

Fonte: Adaptado de Brito et al. (2005)

\subsection{Direcionadores da Logística Reversa}

A geração de programas de Logística reversa é orientada por objetivos estratégicos ou direcionadores que podem ser sinteticamente resumidos como geradores de possíveis diferenciais de competitividade. Podem ser avaliados por diferentes perspectivas e não serem mutuamente exclusivos, porém visam benefícios econômicos de revalorização dos bens retornados, ou objetivam gerar satisfação dos clientes ou ainda visam reforçar a imagem de marca ou empresarial (Leite, 2009; Leite, 2006).

Leite (2006), extraindo as principais ideias de diversos autores, resume a diversidade de dimensões relacionadas aos objetivos estratégicos ou direcionadores (drivers) de Logística Reversa que são resumidas na figura 4:

\begin{tabular}{|l|l|}
\hline Autor & Direcionadores ( drivers) de Logística Reversa \\
\hline Kopicki et al. (1993) & Legislações regulatórias, funcionários e pressões da sociedade. \\
\hline Fuller e Allen (1995) & $\begin{array}{l}\text { Comprometimento da sociedade com preceitos ecológicos; aumento } \\
\text { dos custos ambientais nos negócios; o clima político-legal- } \\
\text { regulatório; os avanços em tecnologia e desenho de produtos; } \\
\text { localização adequada da origem e destino dos produtos de retorno. }\end{array}$ \\
\hline Stock (1998) & $\begin{array}{l}\text { Redução de custos nas operações e nos custos dos serviços aos } \\
\text { clientes; legislações; responsabilidade social. }\end{array}$ \\
\hline
\end{tabular}



retorno e os direcionadores estratégicos?

\begin{tabular}{|l|l|}
\hline Leite (1999), & $\begin{array}{l}\text { Fatores econômicos; tecnológicos; governamentais; ecológicos e } \\
\text { fatores logísticos }\end{array}$ \\
\hline Rogers e Tibben-Lembke (1999) & Cidadania corporativa; obrigações legais; motivação econômica. \\
\hline Dowlatshahi (2000) & Custos; qualidade; serviço aos clientes; meio ambiente; legislações \\
\hline Leite (2003) & $\begin{array}{l}\text { Fatores econômicos, tecnológicos e logísticos e fatores modificadores } \\
\text { legislativos e ecológicos. }\end{array}$ \\
\hline De Brito (2004) & Drivers econômicos; legislativos; cidadania corporativa \\
\hline Fleischman (2001) & $\begin{array}{l}\text { Drivers econômicos, marketing e legais. Aspectos de proteção de } \\
\text { ativos e prestação de serviços. }\end{array}$ \\
\hline
\end{tabular}

Figura 4 - Direcionadores (drivers) estratégicos segundo seus autores

Fonte: Adaptado de Leite (2006)

\subsection{Imagem empresarial e a Logística Reversa}

A conceituação de imagem de uma corporação ou de uma marca é de difícil definição, porém pode ser entendida como o conjunto de sentimentos, ideias e atitudes que os clientes revelam em relação à corporação ou a uma marca. Pode ser traduzida por impressões recebidas e percebidas por diferentes fontes, constituindo-se em um todo personificado, embora com conotações e realces diferentes em cada grupo de clientes. Da mesma forma, estas impressões e informações diferentes podem provocar reações diferenciadas em relação aos concorrentes da marca ou da corporação (Dobni e Zinkhan, 1990).

Schultz et al. (2002) destacam a importância da gestão da imagem empresarial e de suas marcas como uma forma de se distinguir e manter clientes, tendo em vista as diferenças cada vez menores entre as empresas e entre os seus produtos geradas pela globalização crescente. Segundo estes autores, a constituição de uma forte marca corporativa obriga as empresas a buscar formas de se expressar por ações que não estão diretamente atreladas a seus produtos e à própria corporação, mas que reforçam seu significado ao permitir associações positivas com eles. Percebe-se por estas considerações a possibilidade de estas ações serem traduzidas por uma estratégia de Logística Reversa como forma de garantia indireta de posicionamento de marca.

Kotler (2000) lembra a importância e as implicações positivas de reter clientes fidelizandoos. Cita, por exemplo, que uma redução de $5 \%$ na taxa de abandono de clientes pode influir mais que proporcionalmente nos lucros, permitindo maior lucratividade com o cliente no longo prazo.

Figueiredo (2002) corrobora essas ideias ao lembrar que os serviços de pós-venda e de reparação de falhas podem gerar satisfação aos clientes, além de contribuir para sua fidelização, argumentando que os produtos na atualidade possuem características muito próximas e que são os serviços que diferenciam a preferência dos consumidores. Estas considerações apóiam a idéia da Logística Reversa eficiente como uma das estratégias de retenção de cliente e de fortalecimento da marca. Assim, o retorno de produtos, como atividade empresarial, está relacionado a uma orientação estratégica que varia de caso a caso.

As orientações, objetivos estratégicos ou direcionadores (drivers) na Logística Reversa podem envolver resumidamente a prestação de serviços aos clientes, a um reforço ou garantia de imagem corporativa e de marca de produtos, ou a geração de centros de lucratividade resgatando valor de componentes, materiais e de ativos.

Por outro lado, os impactos destes direcionadores nos resultados empresariais podem variar entre empresas de setores diferentes, pelo valor agregado de seus produtos, pelo tipo de atividade das empresas, pela posição da empresa na cadeia de suprimentos, pela preocupação empresarial quanto à sua imagem ou quanto à sua responsabilidade ambiental, entre outros aspectos. No entanto, são poucos os estudos que examinam, de forma específica, o impacto desses direcionadores sobre as políticas de retorno adotadas pela empresa (De Brito, 2004; De Brito e Dekker, 2002; Dornier et al., 2000; Dowlatshahi, 2000; Fuller e Allen, 1995; Kopicki et al. 1993; Rogers e Tibben-Lembke, 1999 e 2001; Leite, 2005). Dessas considerações, depreendem as duas hipóteses do estudo ilustradas na 
Figura 5 :

Hipótese 1: Os motivos de retorno dos produtos influenciam os direcionadores de Logística Reversa nas empresas pesquisadas.

Hipótese 2: Os direcionadores de Logística Reversa influenciam nas políticas de retorno adotadas pelas empresas pesquisadas.

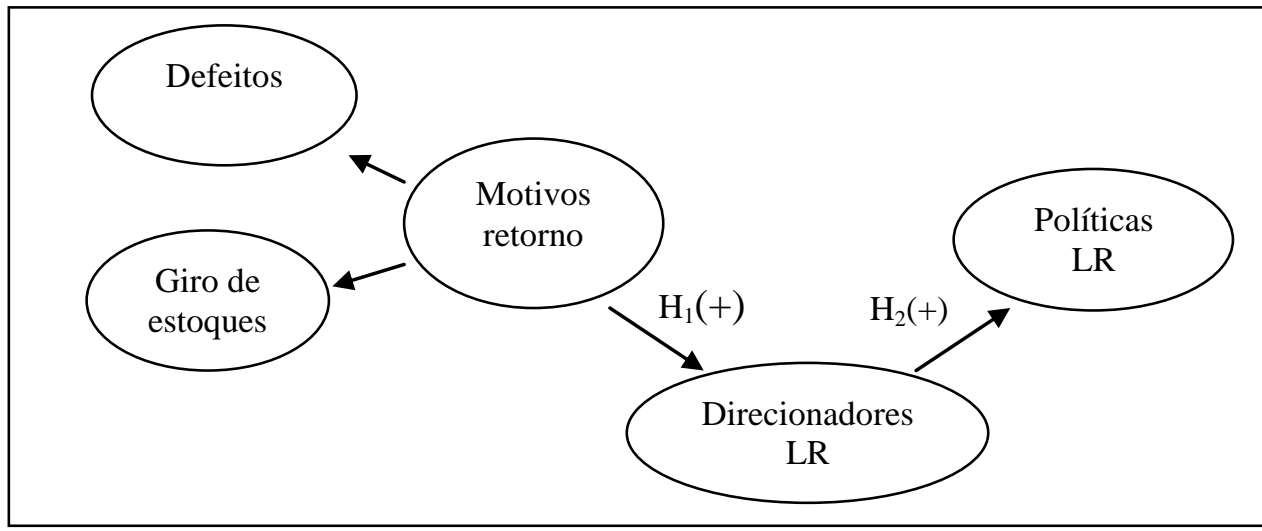

Figura 5: Modelo teórico

Fonte: elaborado pelos autores

\section{PROCEDIMENTOS METODOLÓGICOS}

Este estudo é resultado de uma pesquisa do tipo survey, com abordagem quantitativa descritiva, na medida em que procurou testar as hipóteses enunciadas ao longo do referencial teórico. O questionário original foi constituído de 53 questões, com o intuito de identificar características das empresas respondentes e os hábitos específicos relacionados às práticas de logística reversa. Nesta pesquisa, os dados desse questionário foram utilizados parcialmente no que tange aos motivos de retorno, aos direcionadores estratégicos para logística reversa e às políticas adotadas para o retorno de produtos.

Os indicadores dos construtos utilizados na pesquisa foram: 1) Giro de estoques: questões Q5=Produtos consignados; Q $6=$ excesso de estoque no canal; Q7 = Produtos com baixo giro: Q8 = produtos em término de estação; 2) Defeitos questões: Q9 = Defeitos no produto; Q10 = produtos danificados em trânsito; Q11= produtos com validade expirada; Q12= Conserto ou reparo; Q13 Troca de componentes: 3) Políticas de Logística Reversa: questões: Q25 = Políticas claras; Q27 = Substituição dos produtos retornados; Q29 = Relatório detalhado realizado; Q30 = Política de destino clara; Q36 = Recursos de mão de obra e equipamentos; Q37 = Custos operacionais controlados; Q38 = Pessoal treinado; 4) Direcionadores estratégicos: questões: Q39 = Recaptura de valor econômico; Q40 = Reforço de imagem; Q41 = Satisfação de cliente. No próximo tópico, serão descritos os métodos adotados pela pesquisa e a sua operacionalização.

A pesquisa foi veiculada por uma revista especializada em logística de grande tiragem no Brasil, que hospedou o questionário em seu site deste o final de 2006 até o último bimestre de 2007. Além dos incentivos com chamadas para a pesquisa, a cada novo número da revista, foi enviado aos assinantes mensagem com informações e incentivos à participação na pesquisa, resultando numa amostra composta por 207 respondentes, distribuídos em 14 setores de atividades econômicas. Portanto, dada a natureza da coleta de dados, a amostra foi não-probabilística, o que restringe a generalização dos resultados. Os dados coletados foram submetidos à análise descritiva para avaliação de missing e outliers.

A utilização da escala Likert introduz algum grau de não-normalidade à distribuição, em razão da natureza discreta dos dados obtidos. Para Finney e Di Stefano (2006, p. 302) “[...]a presença de dados não-normais provenientes de escalas ordinais desafiam o pesquisador não somente 
a reconhecer as propriedades de seus dados, mas também, a utilizar técnicas que as acomodem". Nesse sentido, recomendam que: 1) os dados ordinais com distribuições aproximadamente normais provenientes de escalas com, no mínimo, cinco categorias sejam tratados como dados contínuos pelo método de estimação Maximum Likelihood; 2) os dados provenientes de variáveis que possuem cinco ou mais categorias ordenadas que não apresentam distribuição normal, sejam tratados pelo método Maximum Likelihood Robust (ML ROBUST) que ajusta o modelo pela estatística Satorra-Bentler Scaled Qui-Quadrado (SB $\chi 2$ ). Segundo Bentler (1995), o método ML ROBUST também permite determinar estatísticas confiáveis e igualmente estáveis, quando a amostra é relativamente pequena. Portanto, optou-se por utilizar a AFC pelo método robusto, em consideração as recomendações de Bentler relativas ao processamento dos dados provenientes de escalas ordinais.

\section{RESULTADOS}

A análise descritiva dos dados resultou na retirada de 10 respondentes por valores ausentes na maioria das questões e 2 por apresentarem valores discrepantes, resultando numa amostra final com 195 respondentes. Já o processamento a Análise Fatorial Confirmatória, cuja utilização se justifica pela natureza dos relacionamentos em estudo, tem a finalidade de testar relacionamentos entre as dimensões subjacentes nas respostas. A análise se mostrou adequada pela proporção de respondentes por assertiva (195/19), portanto, no patamar mínimo de cinco respondentes por assertiva, conforme sugerido por Hair et al. (2009).

A modelagem dos dados por equações estruturais com os relacionamentos pré-definidos no modelo teórico pelo método ML Robust apresentou os seguintes índices de ajustamento: $\left(\mathrm{SB} \chi^{2}=136,11 ; \mathrm{gl}=95 ; \mathrm{NNFI}=0,818 ; \mathrm{NFI}=0,917 ; \mathrm{CFI}=0,935 ; \mathrm{IFI}=0,937 ; \mathrm{RMSEA}=0,056\right.$ com I.C. $90 \%(0,033 ; 0,076)$. As significâncias estatísticas dos coeficientes estruturais ilustrados na Figura 6 , revelam que todas as cargas geradas no processamento diferem significativamente de zero ao nível de significância de 5\%.

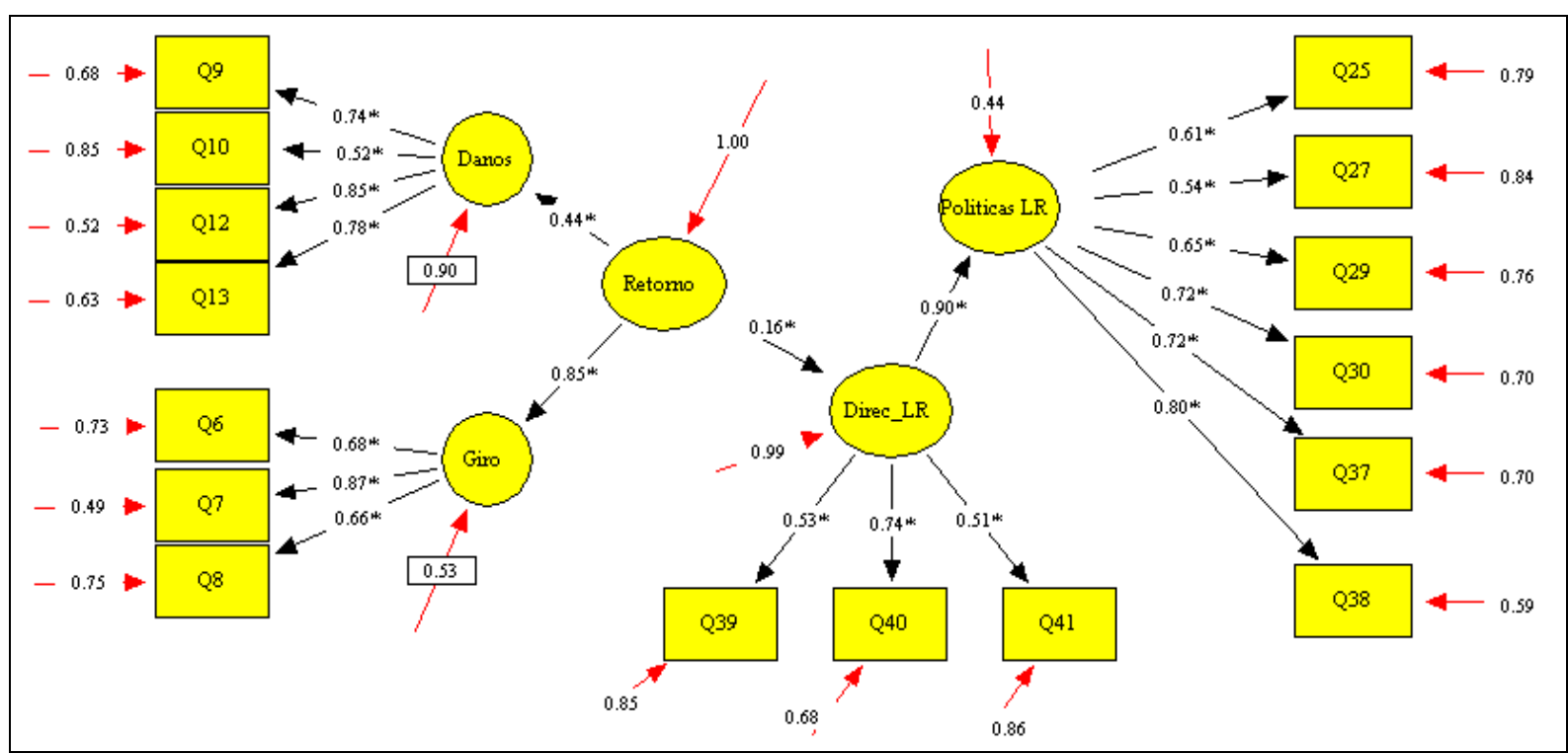

Figura 6: Modelo das equações estruturais

Fonte: Dados da pesquisa

As significâncias estatísticas produzidas no processamento do modelo estão representadas na Tabela 1, onde também podem ser observados os valores das estatísticas "t de Student" e os coeficientes de determinação $\left(\mathrm{R}^{2}\right)$. Os resultados revelam que $2,6 \%$ da variância do construto direcionadores estratégicos de Logística Reversa "Direcionadores LR" é explicada pela variabilidade 
do construto "Motivos do retorno" e que $81,1 \%$ da variância do construto de políticas de Logística Reversa "Políticas LR" é explicada pelo construto "Direcionadores LR"

Tabela 1 - Coeficientes padronizados do modelo estrutural

\begin{tabular}{|c|c|c|c|c|c|}
\hline Relac. Estruturais & Coef. & “t” Student & Sig. & $\mathbf{R}^{\mathbf{2}}$ & Resultados teste \\
\hline H1: Motivos retorno $\rightarrow$ Direc. LR & 0,162 & 2,587 & 0,01041 & 0,026 & Suportada \\
\hline H2: Direc. LR $\rightarrow$ Políticas LR & 0,900 & 5,530 & $1,03 \times 10^{-7}$ & 0,811 & Suportada \\
\hline
\end{tabular}

Fonte: Os autores com base nos dados da pesquisa

Na Tabela 1, também pode ser observado que as magnitudes das cargas estimadas e suas respectivas significâncias estatísticas suportam os relacionamentos propostos no modelo teórico, ou seja: 1) os motivos dos retornos dos produtos influenciam os direcionadores estratégicos para Logística Reversa; 2) Os direcionadores estratégicos para os produtos retornados influenciam as políticas de LR adotadas pelas empresas pesquisadas.

\section{CONSIDERAÇÕES FINAIS}

Os dados coletados mediante as questões necessárias à geração do modelo estrutural mostraram que as hipóteses estabelecidas na pesquisa foram suportadas e a metodologia aplicada se mostrou adequada.

Com a comprovação das hipóteses, os dados permitem afirmar que o motivo para o retorno dos produtos ainda não consumidos, constituídos pelos construtos Giro de estoques e defeitos nos produtos, influenciam os direcionadores de logística reversa adotados pelas empresas. Este resultado não é surpreendente, mas, carecia de comprovação científica. A adoção de um dos objetivos ou direcionadores estratégicos de Logística Reversa deveria estar de acordo com o tipo de motivo de retorno do produto, como por exemplo, nos casos em que o produto somente é reembalado para ser novamente comercializado com o objetivo claro de recuperação do valor econômico.

Ao mesmo tempo, foi possível comprovar a segunda hipótese, ou seja, que os Direcionadores de Logística Reversa estão relacionados com as políticas adotadas pelas empresas. Neste caso, também não parece surpresa que políticas de maior ou menor disponibilidade de recursos dependerão do nível de benefício oferecido à empresa.

Estes resultados garantem uma evolução no conhecimento do comportamento das empresas pesquisadas em relação às ações adotadas na condução da Logística Reversa empresarial e, ao mesmo tempo, sugerem o desmembramento destas variáveis, de forma a serem estudadas mais detalhadamente. Novos conhecimentos poderão ser adquiridos por meio de novas investigações sobre as possíveis diferenças de conduta em Logística Reversa, em razão da natureza da empresa, do tamanho da empresa, de sua posição na cadeia de suprimentos, do valor agregado do produto retornado, entre outros aspectos ainda pouco conhecidos.

\section{REFERÊNCIAS}

Abukhader, M., Jonson, G.(2004) Logistics and the environment: is it na established subject? International Journal of Logistics, 7(2), 2004

Ballou, R.H.(2001) Gerenciamento da cadeia de Suprimentos. Porto Alegre, Edit. Bookman.

Bentler, P. M. (1995) EQS Structural equations program manual. Encino, CA: Multivarite, Software, Inc.

Bowersox, D. J., Closs, D.J.(2001) Logística empresarial. São Paulo: Edit. Atlas. 
Brito, E. Z., Leite, P. R., Silva, A. A. (2008) Hábitos empresariais brasileiros em logística reversa. São Paulo, Congresso SIMPOI.

Brito, E. Z. , Leite, P. R., Povoa, A. (2005) Determinantes da estruturação dos canais reversos: O papel dos ganhos econômicos e de imagem corporativa. Salvador, Congresso ENANPAD.

Cairncross, F. (1992) Meio ambiente : custos e benefícios. São Paulo : Nobel.

Carter, C. R., Ellram, L. M.(1998) Reverse logistics: a review of the literature and framework for future investigation. Journal of Business Logistics. 19(1), 85.102.

Daugherty, P. J., Autry, C. W, Genchev, S. E., Richey, G. R. (2004) Reverse logistics: the impact of timing and resources. Journal of Business Logistics, 25(2).

De Brito, M. P. (2004) Managing reverse logistics or reversing logistics mangement? Rotterdam, Editora Erasmus University Rotterdam.

De Brito, M. P., Dekker, R.(2002) Reverse logistics - a framework. Edit. Erasmus University Rotterdam - Econometric Institute Report EI.

Dekker, R., Fleischmann, M., Inderfurth, K., Van Wassenhove, L.N. (Eds.)(2004) Reverse logistics: Quantitative Models for Closed-Loop Supply Chains. Springer-Verlag:Germany.

Dobni, D., Zinkhan, G. M. (1990) In search of brand image: a foundation analysis. Advances in Consumer Research, 17(1), 110-120.

Donaire, D.(1999) Gestão ambiental na empresa. São Paulo: Atlas.

Dornier, P.P., Ernst, R., Fender, M., Kouvelis, P. (2000) Logística e operações globais. São Paulo, edit. Atlas.

Dowlatshahi, S. (May.June 2000) Developing a theory of reverse logistics. Interfaces. 30(3), 143.155

(2005) A strategic framework for the designe and implementation of remanufacturing oprations in reverse logistics. Internacional Journal of Production Research 43(16).

Faria, A.C., Costa, M.F.G. (2005) Gestão de custos logísticos . São Paulo, Atlas.

Ferguson, N., Browne, J. (2001) Issues in en-of-life product recovery and reverse logistics. Production Planning \& Control, 12(5),534-547.

Figueiredo, K. F.( Julho 2002) Logística do pós-venda. São Paulo, Revista Tecnologistica.

Finney, S. J., Di Stefano, C. (2006) Nonnormal and categorical data in structural equation models. In. Hancock, G.R., Mueller, R.O. (Eds.). A second course in structural equation modeling (pp. 269-314). Greenwich.

Fuller, D. A.; Allen, J.(1995) Reverse Channel Systems. In: Polonsky, M.J., Mintu and Wimsatt, A.T.(ed). Environmental marketing: strategies, practice, theory and research. London, The Haworth Press. 
Giuntini, R., Gaudette, K. (November - December, 2003) Remanufacturing; The next great opportunity for boosting US productivity. Business Horizons, p. 42.

Hair, J. F., Black, W. C., Babin, B. J., Anderson, R. E., Tatham, R. L.(2009) Análise multivariada de dados. (Joseph F Hair, W. C. Black, B. J. Babin, R. E. Anderson, \& R. L. Tatham, Eds.). Porto Alegre: Bookman.

Harrison, A., Hoek, R.V. (2005) Logistics management and strategy. Harlow, edit. Prentice Hall.

Kopicky, R.J., Berg, M.J., Legg, L., Dasappa, V., Maggioni, C.(1993) Reuse and recycling-reverse logistics opportunities. Illinois: Council of Logistics Management.

Kotler, P.(2000) Administração de marketing. São Paulo, Edit Atlas.

Leite, P.R. (2003) Logística reversa-meio ambiente e competitividade. São Paulo, Printice Hall.

Printice Hall, (2 $2^{\mathrm{a}}$ edição).

.(2009) Logística reversa-meio ambiente e competitividade. São Paulo , . (Março/1998) Canais de distribuição reversos. Revista Tecnologística, São

Paulo.

.(2005) Logística reversa: categorias e práticas empresariais em programas implementados no Brasil - um ensaio de categorização. Salvador, Congresso ENANPAD.

.(2006) Direcionadores (“drivers”) estratégicos em programas de logística reversa no Brasil. São Paulo, Congresso SIMPOI.

Majumder , P.; Groenevelt, H. (2001) Competition in remanufacturing. Revista Production and Operation Management. Summer, 10, 125).

Novaes, A.G. (2007) Logística e gerenciamento da cadeia de distribuição. Rio de Janeiro, Campus.

Pires, S.R.I.(2004) Gestão da cadeia de suprimentos - conceitos, estratégias, práticas e casos. São Paulo, edit. Atlas.

Polonsky, M. J., et al (Eds.).(1995) Environmental marketing: strategies practice, theory and research. New York: Haworth Press.

Poulen, T. L., Farris, T. M. (1992) Reverse logistics in plastics recycling. International Journal of Physical Distribution \& Logistics Management, 22(7), 35.

Rogers, D., Tibben-Lembke, R. (1998) Going backwards: reverse logistics trends and practices.University of Nevada:Reno Center for Logistics Management.

.(2001) An examination of reverse logistics practices. Journal of Logistics Business.

22(2).

Rubio, S., Chamorro, A., Miranda, F. J. (2006) Characteristics of the research on reverse logistics (1995 - 2005). International Journal of Production Research, 1-22.

Schultz, M., Hatch, M.J. Larsen, M. H., Keller, K. L.(2002) Building and managing corporate brand equity. Expressive Organization, p. 113-137. 
Stafford, E., Hartman, C. (1996). Quand industriels e ecologistes s'allient, in.Dossier CitoyennetéL'Expansion Management Review, France.

Sheth, J. N., Parvatiyar, A.(1995) Ecological imperatives and the role of marketing in polonsky.

Stock, J.(1998) Reverse logistics programs. Florida: University of South.

Tan, A., Kumar, A. (2006) A decisión-making model for reverse logistics in the computer industry. Singapore, The International Journal of Logistics Management, 17(3), 331-354.

Data do recebimento do artigo: 24/12/2011

Data do aceite de publicação: 17/08/1012 